\title{
HETEROCHRONY AND THE PALEOANTHROPOLOGICAL RECORD: THE ORIGINS OF THE GENUS HOMO RECONSIDERED
}

\author{
BY \\ JOSE MARIA BERMUDEZ DE CASTRO (*) \\ MANUEL DOMINGUEZ-RODRIGO ("*) (sequence of authorship alphabetical)
}

\begin{abstract}
In this paper a critical review is made of the main theories concerning the process of appearance and subsequent evolutionary success of the genus Homo. Furthermore, the current evidence coming from the paleoanthropological record is analyzed in order to establish the interrelation between the biological and cultural factors implicated in that process. It is suggested that the evidence of the paleoanthropological record presumably related to early Homo is basically explicable from the consideration of the strengthening of the social links in the bosom of the group, likely due to the abandonment of an hierarchyzed society in favour of a more cooperative one. This change does not necessarily imply, nor does it exclude the possibility of the formation of stable nuclear families, and probably appeared as a result of a biological change consisting of a decrease of the rate of development, that produced certain prolongation of all life history periods, and some delay in the offset signal for growth (but resulting in paedomorphic adults). As a consequence, there was an increase of the interactive and operative capacities that permitted the emergence of a novel and successful ecological niche under the new environmental conditions arised in the late Pliocene. Other additional heterochrony processes are suggested to explain the subsequent morphological evolution of the genus Homo.
\end{abstract}

RESUMEN En este trabajo se realiza una revisión crítica de las principales teorías relacionadas con el proceso de aparición y subsiguiente éxito evolutivo del género Homo. Se analiza asimismo la evidencia más reciente procedente del registro paleoantropológico, para establecer la interrelación entre los factores biológicos y culturales implicados en dicho proceso. Se sugiere que la evidencia del registro paleoantropológico presumiblemente relacionado con los primeros representantes del género Homo puede explicarse básicamente desde la consideración de un reforzamiento de los lazos sociales en el seno del grupo, relacionado con el abandono de una sociedad jerárquica hacia una sociedad cooperativa. Este cambio no implica necesariamente, pero tampoco excluye la posibilidad de formación de núcleos familiares estables, y probablemente surgió como resultado de un cambio biológico consistente en una disminución de la

(") Colaborador Cientifico.

(“) Museo Nacional de Ciencias Naturales. Madrid. 
tasa de desarrollo, que produjo una cierta prolongación de los periodos de crecimiento y cierto retraso del momento final del crecimiento (pero resultando en adultos paedomórficos). Como consecuencia de este proceso, se produjo un incremento de las capacidades interactiva y operativa, que permitió la emergencia de un nicho ecológico novedoso y eficaz para las nuevas condiciones medioambientales surgidas al final del Plioceno. Se sugieren otros procesos de heterocronia adicionales para explicar cambios morfológicos posteriores en el género Homo.

Key words Hominidos. Modelos de evolución. Heterocronia.

Palabras clave Hominids. Evolutionary models. Heterochrony.

"If early hominids were growing like humans then why weren't they humans?"

Bromage (1986: 310)

\section{INTRODUCTION}

Traditionally, the models that have been proposed to explain human evolution were conceived considering both the significance of the biological processes supposedly implicated, and the interaction of these with what we have named culture in its broadest sense. Cultural factors, however, have been principally used in those models which have searched for an explanation for particular qualitative and quantitative changes observed through the fossil record in the species of the genus Homo (Brace, 1962; Dahlberg, 1963; Wolpoff, 1979; Smith, 1983). Some authors (Bolk, 1926; de Beer, 1948; Keith, 1949; Montagu, 1962; Gould, 1977) have elaborated general models concerning human evolution in order to interpret the remarkable morphological differences that separate Homo sapiens from an ancestor that tends to be identified with chimpanzees and gorillas, our nearest living relatives. It is not hardly surprising that in these models the arguments coming from the observation of the fossil record had a slight relevance. The fossil record obtained up to the late sixties was in fact very limited, and this circumstance lent itself easily to erroneous interpretations. However, the findings of the two last decades, specially those of Hadar, Ethiopia (Johanson et al, 1982), Laetoli, Tanzania (Johanson \& White, 1979), Koobi Fora, Kenya (Leakey \& Wood, 1973, 1974; Day \& Leakey, 1973; Day et al., 1976; Leakey \& Walker, 1985; Brown et al., 1985; Leakey \& Walker, 1988), and Swartkrans, South Africa (Grine, 1989) have permitted to reach a better knowledge of the first stages of hominid evolution, not without, of course, numerous question marks and interpretations, which in a future will also be probably considered as erroneous. Notwithstanding that, a recent revision of the issue of neoteny in human evolution (Shea, 1989) does not include available information coming from the fossil record evidence.

On the other hand, new methods and specially an impresive set of new technologies are being applied to the study of this evidence. Therefore, no research trying to test models of human evolution can be unaware of the data that are potentially offered by the hominid fossil record. In this regard, Bromage $(1986,1987)$ has tested for the first time the model of human evolution generally accepted (Gould, 1977) exclusively by means of the study of hominid fossils, and has presented an alternative model capable of being also corroborated by the fossil record evidence.

But, besides human fossils, the sedimentary rocks preserve a precise information on the some of the activities of early hominids. This information has been used to propose some models of hominid behaviour (Binford, 1981; Isaac, 1983; Potts, 1984), and to approach the ecological niche of the first representants of the genus Homo (Potts, 1988). At present, the elaboration of models concerning human evolution ought to be approached from a broad perspective, using different sources of knowledge mainly Archaeology, Biology of Development, Genetics, Ecology and Palaeontology. Our 
aim here is to make a critical revision of previous models on human evolution, and to use most of the available information to obtain a more comprehensive view of the evolution of our genus. The study in detail of the evolution of other hominid groups (e.g. Paranthropus) is outside the limits of the present paper. However, we will make some references to these groups because, we believe, they are of paramount importance to understand the evolutionary history of the genus Homo.

\section{BIOLOGICAL BASIS FOR A MODEL OF HUMAN EVOLUTION}

The similarities among the infantile individuals of orang-outang, chimpanzee and gorilla and the adults of our own species were not ignored by the scientists of the 19th century (see Gould, 1977). This kind of observations led the dutch anatomist Louis Bolk to elaborate his "Fetalization Theory" throughout several works published in the twenties. According to Bolk (1926), human evolution was characterized by a physiological retardation of development, probably produced by a simple alteration of the endocrine system, that caused the somatic retention of the juvenile proportions present in our ancestors. This claim was strongly rejected and, we believe, unfairly ridiculed because it was not in harmony with the prevailing evolutionary paradigm.

Gould (1977) considers the problem of human evolution from the perspective of the causal relations existing between the modification of the ontogenetic development and the evolutionary changes that separate Homo sapiens from an ancestor, probably very similar to the living anthropoids. Thus, Gould retrieves Bolk's Fetalization Theory, rejecting those aspects incompatible with the valid evolutionary paradigm, and introducing other elements which give a new support to Bolk's insight. Continuing with a previous tradition, Gould (1977) used a considerable and diverse amount of morphological distintions between living humans and other primates as the source of data to elaborate his model of human evolution. In the chapter ten of his book, he only occasionally used the fossil record evidence to corroborate his conclusions.

Gould (1977) considers that we are essentially neotenous, not only because a careful study of our species allows us to elaborate a list of basic paedomorphic features, but because "... a general temporal retardation of development has clearly characterized human evolution. This retardation established a matrix within which all trends in the evolution of human morphology must be assesed" (p. 363). However, not only did he agree with the acceptance that Homo sapiens is the result of a process of neoteny, but he was also encouraged to search for an adaptive significance for the retardation of development in our species. Firstly, he points out that the early stages of ontogeny preserve a great potentiality for news adaptations. Moreover, he thinks that hominids were engaged in a general tendency to increasing size and, as a consequence, to reach an extreme specialization, and, therefore, he claims that "...retardation provided the only "escape" from an ancestral allometry and the only path to a favored adaptation" (Gould, 1977: 397).

The delay in the growth periods is really a common characteristic in the evolution of primates (see Schultz, 1956). This feature, according to Gould (1977), was notably apparent in human evolution through an extended childhood and a delayed sexual maturation. This delay operated sinergistically with other key aspects of the hominization process: upright posture, intelligence, and socialization. The increase of the endocranial capacity, with the resulting increase of the intelligence, was achieved by means of a prolongation of the fetal growth trends; whereas an extended childhood facilitates the obtaining of a greater grade of knowledge, and favours the strenghthening of family links through the consequent and necessary cares required by the offspring (Gould, 1977).

\section{THE FOSSIL RECORD EVIDENCE}

The hominid fossil record would seem to confirm Gould's model to understand human evolution, since the upright posture and a slight increase of endocranial capacity in relation to the great apes

$$
\text { T. P., 1992, } \mathrm{n}^{2} 49
$$


characterize the species of Australopithecus. Moreover, Mann's (1975) original study on the dental development patterns and the skeletal maturation of South African early hominids indicated that australopithecines were characterized by a long childhood dependency period.

The fossil hominids recovered in Hadar (Ethiopia) and Laetoli (Tanzania) in the seventies were a revulsive for theories about human evolution, on demonstrating that there was not a causal and reciprocal relationship between the erect posture and the increase in brain size that characterize the evolution of the genus Homo. During more than two million years certain hominids had an erect posture without showing a significant relative increase of their brain sizes. The encephalization quotients (EQ $=$ the ratio of the observed brain size and the expected brain size) estimated by Martin (1983) were very similar in A. afarensis and A. africanus and, though the respective EQ estimated by this author for Paranthropus robustus and $P$. boisei were greater than those of Australopithecus, these quotients were only slightly higher than the EQ estimated for chimpanzees. The significant increase of the EQ in hominids occurs for the first time with the appearance of the genus Homo. Martin (1983) calculates that the EQ for $H$. habilis was a $80 \%$ higher than that of $A$. afarensis.

On the other hand, Bromage \& Dean (1985) estimated the age at death of specimens belonging to $A$. afarensis, $A$. africanus, $P$. robustus and $H$. habilis based on a scanning electron microscopy (SEM) study of surface manifestations of incremental growth lines in enamel (perikymata). These authors conclude that Plio-Pleistocene hominids had periods of growth and development shorter than those of modern humans, and similar to those of living great apes. Bromage \& Dean's (1985) paper has started an interesting debate among those scholars who have arrived at a similar conclusion (Smith, 1986; Beynon \& Dean, 1988; Conroy \& Vannier, 1987), and those who consider that the methods used by all these authors are not valid to conclude that Plio-Pleistocene hominids had abbreviated growth periods relative to modern humans (Mann et al, 1987; Mann, 1988; Simpson et al, 1990; Mann et al., 1990). Simpson et al (1990) observed, in accordance with previous papers (Broom \& Robinson, 1951; Bromage, 1986, 1987; Smith, 1986; Dean, 1987; Grine, 1987; Beynon \& Dean, 1988), that $A$. afarensis and $A$. africanus exhibited a more ape-like pattern in their dental development sequence; whereas $P$. robustus and $P$. boise $i$ were more human-like in relation to this feature. These last species showed a unique dental development not shared either with modern humans or with living great apes (Bromage, 1986, 1987; Smith, 1986). Simpson et al. (1990), however, consider that each early hominid group have different dental maturational and eruptive patterns as a direct functional response to their different facial growth patterns, and that, therefore, the pattern of dental developmental events cannot be used to establish rates of general development.

With regard to this controversy, we cannot ignore that all Australopithecus and Paranthropus specimens examined up to date have shown enamel incremental growth and dental development patterns that differ from those observed in modern humans, and that suggest growth and development periods similar to those of great apes for the species of the two genera. There are a large amount of data which have permitted to elaborate preliminary charts of development events for Australopithecus and Paranthropus (Aiello \& Dean, 1990). Furthermore, there is a higher correlation between dental and chronological age (Demirjian, 1978) that justifies the validity of the methods used in these studies (Bromage \& Dean, 1985; Smith, 1986). But the essential question to this debate has been established by Bromage: «...if early hominids were growing like humans, then why were they not human in such characters as brain and body size?" (Bromage, 1987: 268).

However, there are not enough data yet to elaborate a chart of development events for early Homo (Beynon \& Dean, 1985; Aiello \& Dean, 1990). The SEM examination of the limited young specimens attributed to early Homo suggests that the crowns of incisor teeth were formed more rapidly than those of modern humans, and that the incisors and first molars emerged close together in the growth period like in Paranthropus and modern humans (Beynon \& Dean, 1988). The only specimen, ER-820, of early Homo that permits a confident analysis, indicates a minimum chronological age at death that represents the $75 \%$ of the estimated age at death using human dental development schedules (Bromage \& Dean, 1985; see also Aiello \& Dean, 1990). Similar estimations

T. P., 1992, $\mathrm{n}^{2} 49$ 
in Australopithecus and Paranthropus indicate chronological ages at death, which range between $51 \%$ and $73 \%$ of the estimated ages using human charts of development (Bromage \& Dean, 1985). Therefore, though the hypothesis that early Homo had a development period shorter than that of modern humans ought to be seriously considered, the claim that «... the trend for prolongation of the growth period had not begun with this group" (Bromage \& Dean, 1985: 2) is still far from being justified.

Bromage (1986) concludes that A. Afarensis, A. africanus and early Homo shared a similar craniofacial remodeling pattern. The differences in craniofacial morphology among these species are due, according to this author, to alterations in rates of remodeling activities. These observations led Bromage to conclude "...that a heterogeneous set of heterochronic processes have combined to define certain adaptive trends in hominids, thus denying the reality of the global concept of neoteny to explain the ontogenetic sequences characterizing the course of human evolution" (p. 3). Bromage $(1986,1987)$ uses the weak evidence represented by the ER-820 specimen, and assumes that early Homo shared a growth and development periods similar to that of Australopithecus. Taking into account the partition of heterochrony between rate and time hypermorphosis considered by Shea (1983) to explain certain size differences of the skull and body weight amongst the African apes, Bromage $(1956,1987)$ concludes that the increase in the brain and body sizes from Australopithecus to early Homo must have been due to rate hypermorphosis; i.e. the changes observed between Australopithecus and early Homo would have happened mantaining the ancestral allometric relation and the ancestral length of ontogeny in time, but increasing the rate of the overall weight growth in the given time. Early Homo, therefore, would be a peramorphic species in relation to Australopithecus. The increase in body size from Australopithecus to Paranthropus was due, according to Bromage $(1986,1987)$, to rate hypermorphosis as well, but on a larger scale.

In order to explain subsequent phases of human evolution, Bromage $(1986,1987)$ examines a paper published by Hemmer in 1969. This author studied the interspecific allometric relationship between the cranial length (g-op) and the face length (pr-ba). Hemmers results pointed out that the transition Australopithecus $\rightarrow H$. erectus was characterized by a transposition of the allometric relationship between the two variables (fig. 3, p. 180). Therefore, this transition did not occur by means of a simple global increase of the brain size since «...such an enlargement would imply a disproportionate enlargement of the facial skeleton, with compression of the braincase and formation of strong crests by the enormously developed jaw musculature, making impossible any increase in braincase capacity" (Hemmer, 1969: 180). According to this author, the change in the allometric level (allometric transposition) between the cranial length and the face length from an Australopithecus type like the "habilis" from Olduvai Bed II must be considered as the moment of appearance of $H$. sapiens in his earliest form (Hemmer, 1969). The origin of this allometric transposition may be found, according to Hemmer, in a change of the ontogenetic growth occurred at a certain time of hominid evolution (Hemmer, 1967).

Bromage $(1986,1987)$ justifies this change by pointing out that the phylogenetic increase of the cranial capacity runs up against the ontogenetic threshold that represents the size of the mother's pelvic inlet. Bromage claims that this limit was reached at or during the $H$. erectus grade, and that subsequent increases of cranial capacity were achieved by means of a fetal growth trajectory for the brain after birth (Bromage, 1986, 1987). This author supports his conclusion in Martin's (1983) observations on the isometric relations between primate neonate and adult brain weigths. The empirical data led Martin (1983) to conclude that at an adult hominid cranial capacity of $850 \mathrm{~cm}^{3}$ (or at the $H$. erectus grade) it was necessary to extend the fetal growth trajectory of the brain into postnatal life. In contrast to other primates, the fetal brain growth trajectory in modern humans continues for a year after birth (Martin, 1983). Bromage $(1986,1987)$ thinks that Shea's (1983) classification of time hypermorphosis (1) fit well the pattern of development of the modern human brain. Therefore, human evolution could be defined by a transition from a developing brain/body

(1) Time hypermorphosis would be equivalent to hypermorphosis in the traditional terminology (Shea, 1983). 
relationship characterized by rate hypermorphosis to a relationship characterized by time hypermorphosis during $H$. erectus times (Bromage, 1986, 1987).

The hypermorphosis process (de Beer, 1930) has been defined as «retardation of maturation with respect to somatic development... Ontogeny is simply prolonged because maturation has been delayed" (Gould, 1977: 255-256), or as "An extension of the juvenile growth period, caused by a delay in onset of maturation" (McNamara: 1986, 10). Alberch et al. (1979) also write "A positive perturbation, $+\partial \beta$, in offset signal (for growth) also produces a peramorphic descendant by a process of hypermorphosis" (Fig. 16, p. 305). Therefore, if we accept that the evolution of the genus Homo was characterized by a process of hypermorphosis, we also accept that: 1) the fetal, infantile and juvenile rates of growth and development, as well as the ancestral growth allometries, were maintained during the course of human evolution, and 2) the differences between early Homo and $H$. sapiens were simply due to a prolongation of the ontogenetic trajectory (juvenile phase of growth).

Evidently, the definition of the process of hypermorphosis and its implications do not agree with Bromage's observations (1986). If the Plio-Pleistocene hominids had growth periods similar to those of the living great apes, then the course of human evolution was characterized neither by an extension of late ontogenetic development (hypermorphosis), nor by the extension of a specific ontogenetic period (e.g. gestation), but by some increase of any of the einfiniten phases (2) that we are able to consider through human development. From an evolutionary point of view, this process can only be explained by a decrease of the morphological development rate (neoteny), and the subsequent increase in the time period of the different growth allometries through the overall ontogeny. This is in accordance with the observations of Martin (1983) that the fetal allometric growth relationship between the brain and body size continues for a year after birth. In this respect, we ought not to consider that the birth time denotes an important moment of our development, but it rather responds to an obstetric necessity: the passage of an organism with a certain size across a canal of certain dimensions.

Therefore, we believe, according to previous claims (Montagu, 1962; Lorenz, 1971; Krogman, 1972; Gould, 1977, among others) that the hypothesis that human evolution (or the evolution of the genus Homo) was characterized by an heterochronic process of neoteny can be still supported. The new evidence furnished by the fossil record indicates that during two million years or more the hominids had growth and development periods at least similar to that of living great apes. But, when did an increase of this period in hominid evolution begin?. Bromage (1986) believes that "Rate hypermorphosis made it possible to alter the brain/body ratios during succesive grades of hominid evolution without requiring any alteration in the length of the growth and development periods" (p. 333). However, a process of rate hypermorphosis implies that the ancestral allometric relation is maintained in the descendant species (Shea, 1983). We agree with Bromage $(1986,1987)$ that a change of the ancestral allometry for the body/brain size relation occurred between Australopithecus and early Homo, but not by means of a process of rate hypermorphosis. The figure 1. is a reproduction from Hemmer's (1969) figure 2, that includes data from hominids recovered subsequently to the publication of his paper. The 1.7-1.9 Myr old specimens ER 1.470, ER 1.813 and OH 24 seem to be approaching the allometric level of the correlation g-op/pr-ba that concern to $H$. erectus/H. sapiens but, in any case, out of the allometric level of Australopithecus. The evidence of the fossil record is still very limited, but it suggests a change in the allometric relation between the face length and the braincase length for the transition Australopithecus $\rightarrow$ early Homo. Hemmer's (1969) observations are compatible with a process of neoteny, and we believe that the change in the ancestral allometric relation for the brain and facial growth may indicate the beginning of this process about 2.0 Myr ago.

Dommergues et al (1986) use the term «hypermorphose néoténique" to define the course of

(2) Human ontogeny ought not be considered as a discrete sequence of several growth phases, but a continuous process characterized by total or partial changes in growth and development rates through the ontogeny, that produces characteristic growth allometries (see Alberch, 1985).

T. P., 1992, $\mathrm{n}^{2} 49$ 
human evolution, arguing that this evolution was characterized by both a decrease in the rate of development and a delay in sexual maturation. Alternatively, we can consider human evolution as the result of a process of neoteny and a delay in the offset signal for growth. We think that in this issue lies one of the main sources of confusion in the debate about human neoteny. We agree with Shea (1989) that the prolongation of growth in time does not equal or require the dissociation and retardation of the patterns of shape change. However, we are out of keeping with this author that a process of neoteny does not imply a prolonged growth in time or delayed maturity. Shea (1989) assumes that in a process of paedomorphosis via neoteny descendant adult size and duration of growth remain unchanged. If we accept this condition strictly, we can discard the process of neoteny as a possible mechanism to explain human evolution. Accordingly, Shea (1989) concludes that «A careful analysis of human development, morphology, and life history patterns reveals little concordance with the predictions of neoteny based on accepted criteria (p. 97). However, Shea (1989) writes: «In humans, we do extend in time the early period of rapid prenatal and early postnatal brain growth..., thus attaining a relatively juvenilized gross skull form with a large, bulbous cranium..., I consider the relative size of the brain and neurocranium as evidence of neoteny (p. 82). We believe that a decrease in the rate of development may imply a delay in the

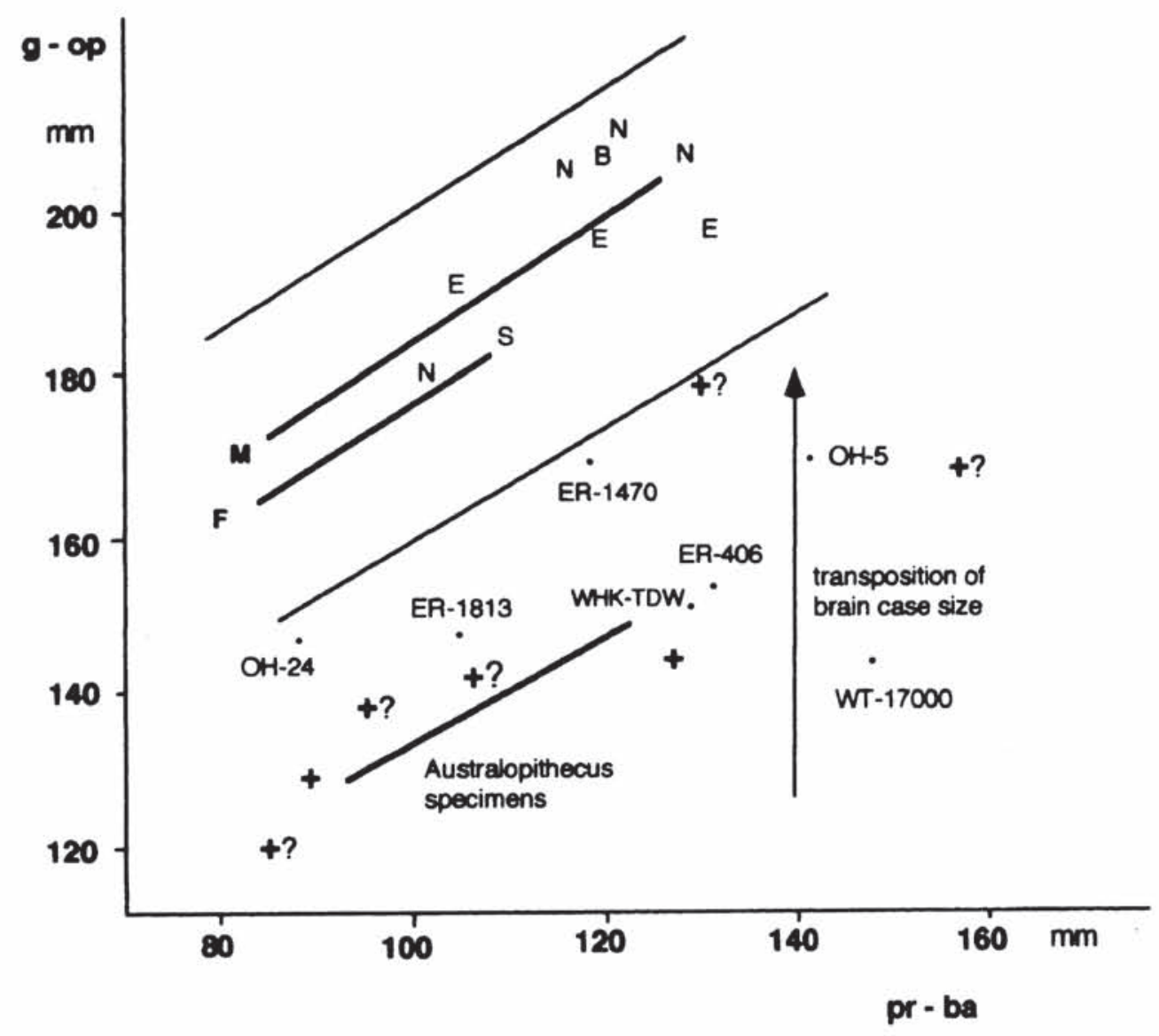

FIG. 1.-Redrawn from the diagram presented by Hemmer $(1969$, fig. 2) for the allometry glabellaopisthion/prosthion-basion ( $g$-op/pr-ba) in a modern population (australian aborigines; M: males, $F$ : females), and in some hominid fossil specimens. Thin lines represent, according to Hemmer, the limits of the range of variation of modern sapiens. We have added data (taken on casts) for the following specimens: ER-1470, ER-1813, ER-406; $\mathrm{OH}-24, \mathrm{OH}-5, \mathrm{WR}-17000$, and WHK TDW (reconstruction of A. afarensis). B: Broken Hill; E: H. erectus; N: Neandertals; S: Steinheim. 
offset signal for growth (and this is an hypothesis to be tested) producing adults larger than the adult of the ancestral species, but not necessarily peramorphic (Fig. 2). We cannot be limited by the rules of precise definitions of heterochrony, but we must consider that heterochrony is a potentially heuristic methodology to understand morphological evolution. A static conception of ontogeny might leads to problems such as those presented here (see Alberch, 1985). Furthermore, we think that the study of particular anatomical features cannot be used to reject the role of neoteny in changes characterizing the evolution of the genus Homo (Lieberman, 1984; Dean \& Wood, 1984; Bromage, 1986).

Bromage (1986) considers that "The concept (of neoteny) is unsatisfactory to explain the multifactorial changes accompanying the evolution of complex anatomical systems". We believe that Bromage's (1986) observations on the similarities between the craniofacial remodeling patterns in Australopithecus and early Homo are compatible with a model of neoteny; this process only implies a change in the rate of development, but not a change in the development or growth patterns. However, we do not defend that the evolution of the genus Homo can be explained as a pure case of neoteny with a delay of the offset signal for growth; but we believe that the increase in the ontogeny time period was the main process characterizing human evolution, and that this process was produced by a decrease in the rate of development. Other heterochronic processes affecting the whole organism or particular anatomical regions could have influenced the evolution of the genus Homo. For instance, the fossil record suggests that some increase of the overall growth rate may be responsible for the presence of certain traits, which have been considered as synapomorphies in all Middle Pleistocene hominid groups. The thickened tabular bone in the cranium and thickened cortical bone in the postcranium (see Kennedy, 1985), as well as the considerable amount of dentine deposition in the anterior teeth, which characterizes all specimens usually attributed to $H$. erectus reflect, in our opinion, a certain increase of the overall growth rate in these hominids. The

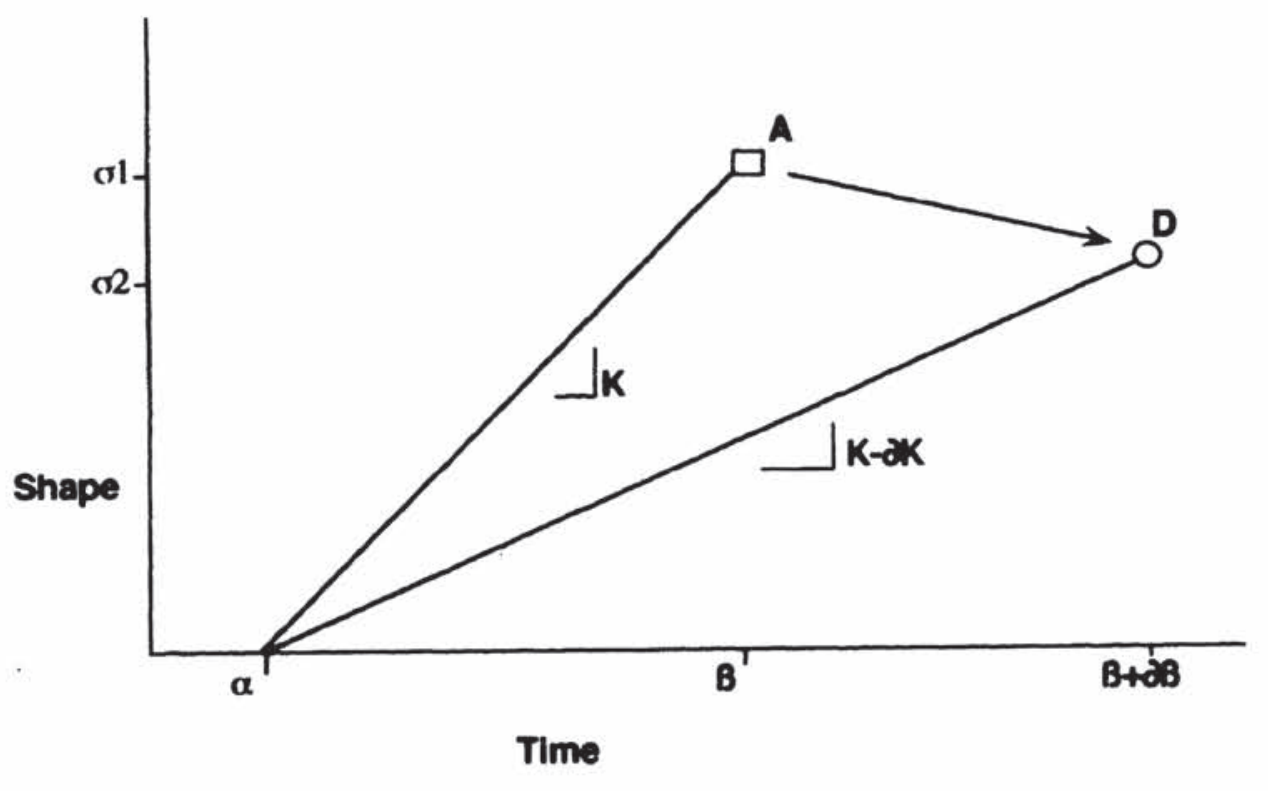

Fig. 2.-Ontogenetic trajectories of Homo sapiens (D) and his ancestral species $(A)$. A negative perturbation in the rate of development of $A$ produces a change in the ontogenetic trajectory, and results in a paedomorphic descendant by a process of neoteny. This delay do not necessarily implies that the descendant species trascend the ancestral shape, and were peramorphic in relation to $A$ (which depends on the value of $\partial K$ ). However, our model implies that the adults of the direct ancestors of modern humans were located in some place along the line $A D$. $\alpha$ : onset age of growth; $\beta$ : offset signal for growth; $K$ : shape growth rate during the growth period. Based on the model of Alberch et al. (1979). 
superposition of this growth rate increase to the changes in the time period of the ancestral allometries may explain the presence in $\mathrm{H}$. erectus of some features which, we believe, are difficult to understand in adaptive terms, though other ones may arise as anatomical solutions to biomechanical problems (see Smith, 1983). Though the discussion of this problem is outside the limits of this work, we suggest however that these insights may constitute a potentially useful methodology to focus future studies of hominid variability and evolution.

\section{INFERENCES FROM THE ARCHAEOLOGICAL RECORD}

Behaviour - an ecological factor of vital importance for the understanding of evolution, as the intercessor among the individual, the community and the environment - is a perfect measurer not only of the degree of adequacy of the different kind of species, but also of the index of their behavioural development, which can be observed largely in the extent of their operativity in the processing of information. This ability, so much more complex as the species is evolved, from a neurophysiological consideration, is responsible for the degree of social interaction within groups, only conditioned by the proximity and tolerance among the individuals that form part of them and the use they make of territory.

It would be right to state that a species's behaviour is therefore limited by the extent of its evolutive development - which grants a greater degree of possibilist reaction as the magnitude of the instinctive conduct decreases - and by the conditionalities set forth by the environmental parameters. Bearing in mind' that behaviour is a crucial factor in the global interpretation of evolution - which the traditional paradigm has hardly considered- it becomes necessary to value it adequately by using such criteria. Thus, since we are interested in the causes of somatic changes, then we should also focus our attention on behavioural alterations which, though in some instances could be easily explained in terms of adaptative readjustments due to a modification of the parameters that rule the selective pressure, in other cases its exegesis should be worked out in the same terms as the phenotype alterations. Considered in this way, it could be appropiate to talk about behaviour evolution, whose comprehension should be made through a "phylogenetic" interpretation of behaviour itself in a little scale. That is to say, a conduct change is only possible from a previous pattern whose alteration makes feasible the appearance of a new way of reaction, that derives, strictly speaking, from the anterior form. This criterion, implicit in most of the ethological research, has helped to create comparative models that have permitted to observe the existent variability in order to evaluate it properly.

At some time before two million years ago a new kind of behaviour appears in the hominids's realm, coinciding with the oldest archaeological record, whose general characteristics differ-in some aspects in a radical way- from the basic behavioural pattern of the primate ambit. After nearly two decades of testing the Plio-Pleistocene living floors of East Africa to evaluate their degree ofintegrity and resolution, a consensus was reached about the dynamics of the formation of such artefact-plus-bone concentrations, attributing their main authorship to hominids. This behaviour, apart from the social implications that can be inferred, may be set up according to the next evidences:

1. The archaeological sites appeared as a result of the reiterated accumulation of carcasses that were transported from the points where they were obtained to central reference places - with recurrent dispersal and reunion of the group at this chosen localities - to consume the meat they contained (Bunn, 1981, 1982, 1983; Bunn \& Kroll, 1986; Isaac, 1983a, 1983b, 1984; and Potts, 1983, $1984,1988)$. This means a series of innovations with regard to the general lines of the previous subsistence behaviour:

T. P., 1992, $\mathrm{n}^{2} 49$ 
A. Meat eating in significant quantities; at least in an average substantially greater than the rest of living primates.

B. Postponement of food consumption.

C. Transport of food and communal consumption at a central place.

D. A greater capability of territorial structuration, that would have involved an extensive degree of forethought and planning and/or strategic anticipation.

2. The presence of lithic tools and stone debris in the sites can be accounted for its employment in the processing of carcasses, which permited to have access to as wide a taxonomic variety as the archaeological record demonstrates (Bunn, 1981; Potts \& Shipman, 1981; Toth, 1982). However, this fact reveals a series of abilities unknown in extant apes:

A. The capability of elaborating operative chains, that get further than the mere metabiologic usage of certain vegetable and lithic items by some superior primates.

B. Valoration of the raw materials in the manufacture of artifacts to the extreme of transporting it along several kilometers.

This new behaviour, defined through the central-place foraging hypothesis (Isaac, 1983) is due, in its whole consideration, to an increase in the sociability of the hominid groups responsible for the living floors and in their capability of processing the information received from the environment.

Nevertheless, what was the real cause of this behaviour? At first sight, it might be thought that a change in the ecosystem was the instigator of the whole process. The available data indicate a climatic alteration at the end of the Pliocene, which consisted of a decrease of the humidity index that would have provoked a new configuration of the east african flora and fauna (Bonnefille, 1976; Harris, 1983; VVAA, 1985). However, even with such readjustments, the Plio-Pleistocene savannah was somewhat moister than it is today. It is therefore very likely that the bush areas occupied a larger land extension than they do in the modern ecosystem. But even so, the alteration suffered by the environment almost 2,5 million years ago was tremendously important because it helped to reduce the habitats of several species, to promote new adaptative trends (specially in perissodactyla) and because it offered a new space to newly developed strategies. This is just what seems to happen to the hominids: whereas the australopithecines had to adapt themselves to a more reduced habitat, the primigenial members of our genus knew how to enlarge their ecological niche to avail of the resources offered by the open plains.

However, the behaviour inferred from the archaeological record does not seem to respond to a simple adaptation to the new conditions issued in the environment. The general behavioural pattern necessary for the anthropic accumulations need, as much as a new way of adaptation, a series of abilities and operative capabilities, only adquired through an internal process, that exceed those observed in extant apes. Thus, this behaviour is not due to a mere adaptative readjustment, always comprehensible within a strictly ethological frame, but to a new adaptation issued from an improvement of the capability to process information, which would be itself related to a redefinition of the social ties. The lack of this element would have prevented a conduct of this kind from having appeared beforehand.

Earlier we have interpreted the somatic changes that emerge with Homo from a heterochronic consideration of neoteny. Now we mean to assess that such a process is also the reason of the behaviour responsible for determined anthropic accumulations. If these are due to the establishment of central places where food is transported and presumably shared, in a cooperative attitude, it may be asked what kind of social and biological changes caused such reaction.

Concerning the first type of alteration, it should be stated that a society becomes more cooperative as the pressure from the exterior is greater. This can be observed in the primates that inhabit a forest ecosystem and those who live in the savannah. In the latter, the vegetable resources are scarcer and more scattered and the competition for them is stronger. Before such circumstances, the usual action is an increase in the variety of the products consumed by adopting a diet that

T. P., 1992, n 49 
tends to become omnivorous. As the savannah is more hostile than the forest, due to the existent pressure on resources and the number of predators that occupy an ecological niche in that ecosystem, the way that primates behave is using an adaptative strategy of reinforcement of the social links, together with a development of the agression instinct. However, even though such modifications have been carried out, the social structures that lie beneath are still the same, with the maintenance of the hierarchies and the reproductive and subsistential strategies that are common to the rest of primates.

The conclusion that can be drawn from the observation of the archaeological record, nevertheless, is that the general behavioural pattern of subsistence is abandoned in favour of a more planned conduct, that must have emerged in more cooperative societies, as a result of further increasing the reinforcement of the internal links. But, what promoted such change in the social relationships? One could argue about the possibility that some hominids simply became more intelligent. However, the increase of intelligence means a raising of the degree of potentiality on the environmental operativity that does not necessarily imply a readjustment of the subsistence strategies. That is, the improvement of the way of processing information would have reported a greater capability of acceding to a wide spectrum of resources - among which meat would be an important element-, but the way of consumption should not be altered. It could only be expected a slight postponement of meat ingestion because of the displacement of the carcasses obtained to other places, in order to be safe from the open-plain predators. But if this had been realized according to the primate behavioural pattern, the displacement of meat pieces would have been comparable to the action of determined carnivores, which does not propiciate the formation of the bone concentrations that we observe in the archaeological record, because it always depends on the place that carcass is obtained. The archaeological bone accumulations, however, seem to indicate the establishment of referential places previously to the meat obtainment. Thus, the postponement of food consumption could be attributed not only to avoid the hostility of the open areas, but mainly to bring a part of it (or the whole of it) to the rest of the group (Fig. 3). This fact together with the hypothesis that in this kind of action only a fraction of the group would have participated (What could have been the role of the females with offspring in the obtainment of carcasses?), concedes a greater consistence to the interpretation that this behaviour is due to as much a necessity of increasing the internal cohesion as to the adquisition of a better intelectual capability, because both factors are intimately related. If this assumption is not discussed, then the next step will be the discernment of the reasons of such a social reinforcement. If this one was favoured by the raising of intelligence, on an environmental stage with well-defined criteria, it is logical to think that the initial change was a biological one.

Previously, from an heterochronic perspective, we have argued that the physical traits that appear with our genus might be explained by one of the next possibilities: rate hypermorphosis or neoteny. If we consider the first of them, the neonates would have been taller than their predecessors and perhaps their morphological pattern could have been slightly altered. But a change due to rate hypermorphosis would not create a helpless offspring that needed more attention and a longer period of living together with their progenitors. So, if early Homo had experienced this sort of change, keeping the same development pattern as their predecessors, the social relationships within the group should not be altered significantly. A neotenical process, however, would have imposed a change in the nature of this relationships, because of the prolongation of the development period, increasing, therefore, the lenght of the infantile and juvenile stages and making the progeny at the same time more defenseless and needy of paternal care. This fact could have caused the need of a tighter social cohesion to take care of the offspring, this being the key to the alteration of the relationships among the individuals of the group and giving rise to a cooperative behaviour, which is the one inferred from the archaeological record.

The neotenic argument proposed to account for the origin of our genus is not new. Several authors have used it for the same purpose (Washburn, 1967; Lorenz, 1971). Nevertheless, few of

T. P., $1992, \mathrm{n}^{2} 49$ 
them have investigated further into its causes and its close relation to the behaviour that appears in the end of the Pliocene. Isaac (1983) interpreted it in a convincing way, according to what he called "culture-brain system», which consisted of treating brain and culture as co-evolutive elements that were likely to have evolved as a single adaptative complex: Culture appears because brain evolves, but also because «enlarged brains require prolonged infant dependency and high-quality nutrition» clearly alluding to a process of neoteny and a dietary improvement.

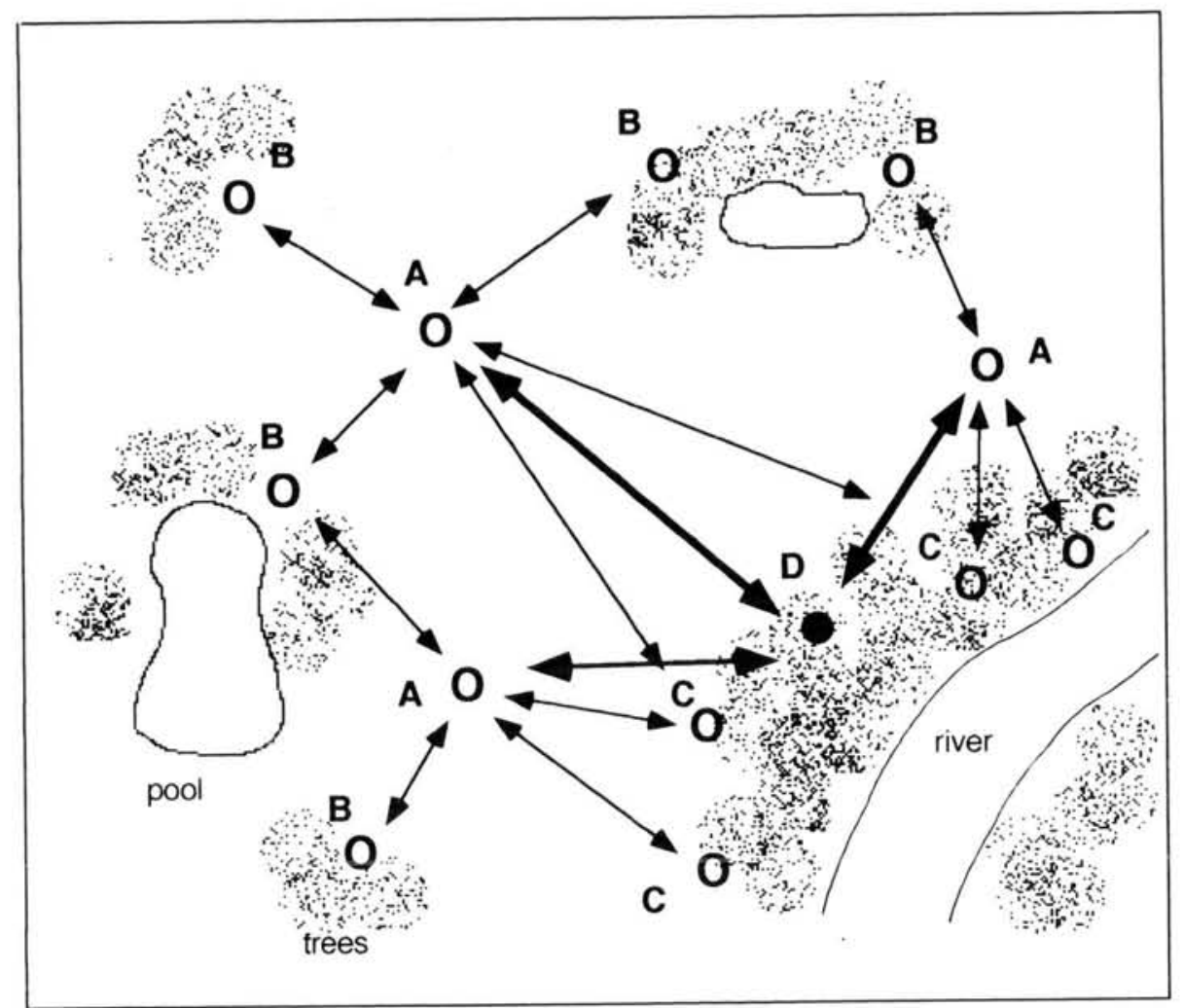

FIG. 3.-The formation of the archaeological record responds to planned actions, where the hominids involved would have established reference places or common operative points, not necessarily identified with home bases, previously to the transport of meat resources. If these hominids had kept the basic subsistential primate pattern, the processing of carcasses would have been carried out in situ $(A)$, where the carcass was obtained-or in a nearby sheltered place (B), always conditioned by the exact point of the obtainment of the carcass itself. However, the preference for areas of dense vegetation close to rivers and lakes $(C)$, as the sites might indicate could be due to the existence of a wider spectrum of lithic resources than in the open-plain areas (A, B), and because the number of predators is more reduced. But this being the only reason, there would not exist any opportunity for bone accumulations, as the carcasses could have been transported to any place indistinctly $(C)$. Nevertheless, though this accumulation could have happened, due to the hazardous incidence of the hominids on the same spots, during a lapse of time that might span an unlimited period, it would not have been restricted to so a reduced area as the archaeological sites are.

Therefore, bearing in mind these considerations and the presence of foreign raw material in a vast number of sites (which contradicts the idea that sites were brief episodes in the subsistence behaviour), it might be concluded that these artefact-plus-bone concentrations were central-reference places created under new social and biological circumstances.

\author{
T. P., 1992, $\mathrm{n}^{\circ} 49$
}


Basically, the retardation of development observed in Homo is just the continuation of the general trend to its prolongation in extant apes, which increases itself according to their degree of evolutive complexity (Shultz, 1956). Furthermore, between the genus Homo and the living anthropoids there exists an authentic variation in the time parameters of each of the development phases (a circumstance that is accompanied by opposed subsistence strategies), which gives further support to the hypothesis that the intermediate links between both extremes must be found in the fossil record.

But if the retardation of such process results quantitatively more important as the evolutive scale gets more complex and its apparition in Homo is perfectly comprehensible following these criteria, why were the consequences so drastic? The well-defined trend to the prolongation of the infantile and juvenile periods has deeply influenced primate behaviour. The close dependency of youth gives them the possibility of learning adults's reactions. If this is still prolonged then it may be observed a raise of adquired behaviour in detriment to inborn conduct. This leads to the conclusion that the longer the parental dependency is, the greater the range of behavioural options become -helped by a better understanding of the information- which turn those who are involved in it into more intelligent beings. However, an increasing retardation of development means a postponement of the addition of new generations, which is vital for the survival of the species limited to only one new individual per enlightment. This trend of a $" \mathrm{~K}$ " reproductive strategy is as much pronounced as the degree of complexity of primate evolution becomes greater. Whereas in prosimii multiple enlightment is still common, in the great apes there is a reduction of it and the normal rule is one descendent per parturition. But the really important factor is that the more evolved a primate is, the longer the length of time is between one enlightment and the next; thus becoming the "K" strategy more extreme. But if this is carried out to a determined limit-where certain threshold is trespassed -it supposes a great risk for the species, which is set on the verge of extinction if any kind of selective readjustment occurs (Lovejoy, 1981). This is probably the reason that the differences in the duration of gestation and spacement of successive descendents among anthropoids are rather unimportant; even though some of them are superior to the others in evolutive terms. This fact is due to their being just in the limit of the "K» strategy, where any attempt to get further could be prejudicial.

In order to prolong the development period and to enjoy its consequences, it would be necessary to alter the basic subsistential pattern and, therefore, the social structure, as Lovejoy (1981) correctly states, turning from a hierarchical organisation to a cooperative one, and looking after the offspring in a proper way, with all that this represents in the alteration of feeding behaviour. Nevertheless, we do not agree with Lovejoy's hypothesis as to the moment of appearance of this modification, changing it from the genesis of bipedism, as he states, to the origin of Homo. One of the reasons that impel us to do so is not only that the first somatic indications of such process appear with our genus, but also that a behavioural change of such a magnitude needs an operative capability that superior primates - and possibly first hominids too- lacked. And the most ancient evidence of this ability is demonstrated by the appearance of the archaeological record which, in turn, coincides with a relevant brain enlargement in Homo with regard to the australopithecines, being the craneal capacities, in some cases, the double.

This authentic increase of intelligence would have caused a wider operative ability in the exchange of information, creating a more complex capability of reaction towards the environment and the society. The development of attitudes of reciprocity within the group would have led to a greater cooperation, and the processing of information with more efficiency would have augmented the operativity on the environment by making it more intelligible. This could have favoured the formation of central places, like those that appear on the record, increasing the efficacy of moving through diverse habitats, and creating a new ecological niche not constrained exclusively to a concrete kind of habitat.

They would have developed also the capability of estimating the raw material and of linking operative chains capable of transforming it into lithic industry, with which access to a diversity of 
meat resources could be gained, and which was also probably used to elaborate other sorts of instruments. The basic subsistence primate pattern that demands the inmediate satisfaction of instinct is abandoned as the first traces of a conduct that responds to the planning of actions that go beyond the former appears.

This amplification of the environment comprehension could be a logical consequence of the retardation of development, which would have meant not only a quantitative increase of the dependency period, but also a qualitative augmentation of it. That is to say, the neonate could have had more time to learn and more capacity to do it. The prolongation of parental care would have been responsible of the transmission of information to the progeny, which would get in this way all the knowledge needed for survival. This means at first a longer maternal dependency -it is likely that males participated in this phase too- in the infantile stage, where the attentions received would have prepared the offspring, psycologically, for the development of their faculties. During the juvenile phase the progeny would have enlarged their contact area, from the family group to the social group, learning from the adults the behaviour that would be indispensable to subsistence and to strengthening the group's organization. This would have reduced the inborn conduct to its basic expression in favour of the adquired knowledge, potentially more useful.

However, we have seen how this trend to the «K" extreme has some important consequences for the members of the group, who must adopt a subsistence strategy whose basic lines differ from those of the rest of primates. It has always been said that the main reason for the change could have been the care of a defenceless offspring. If this had been the only motif, the species could have risked extinction because with the prolongation of the development period the lapse of time between successive enlightments would have been greater. Thus, if the degree of intelligence is increased and the social links are redefined, there is, in turn, a retardment in the generational renovation, which is risky for a species whose new ecological niche includes dangerous habitats, and that needs to be more prolific than their evolutive congenerers - who preferred the sheltered areas - to compensate the loss of individuals. The success, of the new behaviour, therefore, could be accounted for by the next reason: The prolongement of development could not have needed to alter the length of time from a parturition to the next one, if the augmented progeny was properly looked after. So, just by keeping the anthropoid birth parameters and by enlarging development at the same time - with an increased parental dependency - the social reorganization would be then more intelligible, because cooperation would have become necessary not as much to care for the defenceless offspring, but for the increasing number, so that the infant would have needed, therefore, the participation of all the members of the group for their survival.

This hypothesis could be corroborated by the character of diet itself. Some authors assess that to develop and keep a brain like Homo habilis's brain, it is essential for diet to be rich in energetic terms (Martin in Lewin, 1982). Isaac (1983), in his "brain-culture" system, states that a dimensional change in brain requires an alteration of the index of calories and proteins of the food consumed, being necessary a high-quality nutrition only possible if eating meat resources. Thus, the significant meat consumption, whose vestige is clear in the archaeological record, made these innovations feasible.

One of the further consequences that this change of diet could have meant is that it might have made females more prolific, predisposing them to be more fertile (Darwin, 1871).

When talking of the passage of a hierarchical society to a cooperative one, with males engaged in breeding, it is commonly assumed the formation of stable couples or familiar nuclei (Lovejoy, 1981). If males had to participate in this task, it is logical to suppose that they were integrated in a social system that resulted, essentially, almost utterly human. To argue the motivations of this relationship it has been proposed the reciprocal interaction argument, where both, male and female, could have been beneficiary of the new system. Lovejoy's hypothesis is particularly shocking in this regard, as it pretends that males would have accepted such an association in return of permanent sexual relationships - disentangled from estrus-, whose origin must be sought in a slow replacement of the instinctive attraction by another of epigamic character. But this, in our opinion, results

\section{T. P., 1992, $\mathrm{n}^{2} 49$}


extremely premature as the epigamic attraction is the result of a psicophysiological organization only observable in modern man. Placing its origins at the beginning of the Pliocene, as Lovejoy does, would mean accepting that the capability of abstraction existed in such a remote time, where there is no evidence thereof.

As a matter of fact, males could simply have consented to cooperate with females without needing to get from them a sexual satisfaction of that kind. Cooperation could basically have been carried out by means of a survival strategy, as it happens among hilobatids, in which there is a clear precedent. The formation of stable couples, however, is not indispensable to maintaining a system like the one proposed. Males could have felt obliged - by a mere necessity of adaptation to the environment - to participate in the custody of the progeny, not only in a defensive way as the rest of primates do, but getting the meat necessary for an improvement of diet, too. They would have cooperated in the social distension, making it possible for the offspring to enjoy the didactic potential of a relationship of this kind.

If this had been the case, it might be expected a relevant dimensional variability due to the sexual dimorphism existent in a system with these features. In this respect, the observations of the size and shape variability that has been found in Homo habilis (see Chamberlain, 1999) have led some authors (eg. Groves \& Mazak, 1975; Stringer, 1986 y Liebermann et al., 1988) to conclude that more than one species are represented in the early Homo hypodigm or that sexual dimorphism could explain this observed variation (White et al., 1989 y Tobias, 1985). However, other authors state that the fossil remains do not seem to offer a solid basis to support any of the options (Harcourt et al., 1981; Martin \& May, 1981).

Thus, with the appearance of families or with the maintenance of a poligamic society of cooperative males, the retardation of development together with an ostensible increase of intelligence would have benefitted the shift to a more solidary behaviour that, in turn, would have propitiated a longer parental dependency and a greater capability of informative operativity.

Bearing in mind the quantitative improvement of diet, this could have had demographic consequences that, together with a social system of reciprocity, would have set the basis for the expansion of our genus, which would reach its height with the abandonment of the African continent and the extinction of the rest of the hominids.

\section{CONCLUDING REMARKS}

Heterochrony is a useful way to study evolutionary changes in human evolution. In this respect, we consider that the concept of neoteny has a lot to offer to understand the first stages of human evolution (contra Bromage, 1986), and that it is not a bankrupt concept to explain some aspects of our development (contra Shea, 1989). Modern humans are not differentiated from living great apes, and probably from Australopithecus simply by a prolongation of the growth period (or by a delay of the offset signal for growth). This is a peramorphic process that would have happened via time. hypermorphosis (= hypermorphosis). Instead, we are characterized by an extension of all our life history periods in relation to the great living apes. To our knowledge, no heterochronic process defined up to date, except neoteny, fit this human feature; we need either to propose a new peramorphic process of heterochrony in which the rate of development and, therefore, the ancestral allometries remain unchanged, but there is an extension of the entire growth period, or simply to accept that this extension was produced via neoteny by a decrease in the rate of development. The pattern of brain growth in modern humans (see Martin, 1983) advocates for a such decrease, though further experimental research on heterochronic processes would be necessary to answer these questions. In any case, we believe that the beginning of the extension of the different growth periods was probably related to the speciation that supposed the appearance of the genus Homo. This would help to explain the appearance of the archaeological record, which is better understood from a view of social reorganization due to a biological change in the operative and interactive 
capabilities and to an alteration of breeding behaviour, that would have caused the necessity of becoming a more cooperative society.

We are firmly persuaded, however, that a simple process of neoteny cannot account for all the evolutionary changes characterizing our lineage. We think, for instance, that the presence of certain synapomorphies (long bone shaft thickness, thick bone of the cranial walls and mandibular bone, or a considerable deposition of dentine in the incisors) in those Middle Pleistocene hominids which have been generally attributed to $H$. erectus, or considered as "archaic" $H$. sapiens (see Wolpoff, 1980) may be explained by an increase of the overall growth rate. If this is true, the so-called multiregional model to explain the origin of anatomically modern human populations (see for instance Wolpoff et al., 1984; Wolpoff, 1989 or Kramer, 1991) ought to assume that the evolution of diverse populations in different parts of the world was characterized by a new decrease of the growth rate to get the gracilization that is common in all modern human populations. But, how is it possible to justify such a parallel evolution? In contrast, the acceptance of the single origin or replacement model (see for instance Howells, 1976 or Stringer \& Andrews, 1988) might imply the hypothetical existence of an African Homo population which did not experience an increase of the overall growth rate similar to that of $H$. erectus. This hypothetical population would have not shared with $H$. erectus those derived features that arose from the increase of growth rate. Therefore, those features that define the gracile skeleton of living humans would be plesiomorphous, and not derived ones, as suggested by Stringer \& Andrews (1988). These insights have important phylogenetic and taxonomic implications, and merit further research and discussion from a cladistic and heterochronic view (see Fink, 1982).

\section{ACKNOWLEDGEMENTS}

This research has been supported by the DIGICYT projects PB88-0120 and PB90-0126-C03-01.

\section{BIBLIOGRAFIA}

Aiello, L. \& Dean, CH. (1990): An Introduction to Human Evolutionary Anatomy. Academic Press. London.

ALBERCH, P. (1985): "Problems with the interpretation of development sequences". Systematic Zoology, 34: 46-58.

Alberch, P.; Gould, S. J.; Oster, G. F. \& WAKE, D. B. (1979): "Size and shape in ontogeny and phylogeny". Paleobiology, 5: 296-317.

BEynON, A. D. \& DEAN, M. C. (1988): «Distinct dental development patterns in early fossil hominids». Nature, 335: 509-514.

Beynon, A. D. \& Wood, B. A. (1987): «Patterns and rates of enamel growth in the molar teeth of early hominids». Nature, 326: 493-496.

Binford, L. (1981): Bones, Ancient Men and Modern Myths. Academic Press. New York.

BolK, L. (1926): Das Problem der Menschwerdung. Gustav Fischer. Jena.

BonNEFILlE, R. (1976): "Palynological evidence for an important change in the vegetation of the Omo basin between 2,5 and 2 million years agom. In C. Howell, R. Leakey, G. Isaac \& Y. Coppens (eds.): Earliest Man and the Environments in the Lake Rudolf Basin: Stratigraphy, Paleoecology and Evolution. The University Chicago Press. Chicago: 421-431.

BRACE, C. L. (1962): "Cultural factors in the evolution of the human dentition". In M. F. A. Montagu (ed.): Culture and the Evolution of Man. Oxford University Press. New York: 343-354.

Bromage, T. G. (1986): A Comparative Scanning Electron Microscope Study of Facial Growth and Remodeling in Early Hominids. Ph. D. Thesis. University of Toronto. Canada.

- (1987): "The biological and chronological maturation of early hominids". Journal of Human Evolution, 16: 257-272.

Bromage, T. G. \& DeAN, M. C. (1985): "Re-evaluation of the age at death of inmature fossil hominids". Nature, 317: 525-527.

Broom, R. \& Robinson, J. T. (1951): «Eruption of the permanent teeth in South Africa fossil ape-men». Nature, 167: $167-443$.

T. P., 1992, $\mathrm{n}^{2} 49$ 
Brown, F.; HaRris, J.; LeAKeY, R. \& WALKER, A. (1985): “Early Homo erectus skeleton from west Lake Turkana, Kenya». Nature, 316: 788-792.

BunN, H. (1981): «Archaeological evidence for meat-eating by Plio-Pleistocene hominids from Koobi-Fora and Olduvai Gorgem. Nature, 291: 574-577.

- (1982): "Meat-eating and Human Evolution: Studies on the Diet and Subsistence Patterns of Plio-Pleistocene Hominids in East Africa». Ph. D. dissertation, University of California, Berkeley.

- (1983): "Evidence on the diet and subsistence patterns of Plio-Pleistocene hominds at Koobi Fora, Kenya, and Olduvai Gorge, Tanzanian. In J. Clutton-Brock \& C. Grigson (eds.): Animals and Archaeology: Hunters and their Prey. B.A.R. International Series. Oxford: 21-30.

BunN, H. \& KRoLL, E. (1986): "Systematic Butchery by Plio-Pleistocene Hominids at Olduvai Gorge, Tanzania». Current Anthropology, 27: 431-452.

Conroy, G. C. \& Vannier, M. W. (1987): «Dental development of the Taung skull from computerized tomography». Nature, 329: 625-627.

DARWIN, C. (1871): The Descent of Man. Modein Library. New York.

DAY, M. H. \& LEAKEY, R. E. F. (1973): «New evidence of the Genus Homo from East Rudolf, Kenya In. American Journal of Physical Anthropology, 39: 341-354.

Day, M. H.; Leakey, R. E. F. \& WalkeR, A. C. (1976): "New hominids from East Turkana, Kenya". American Journal of Physical Anthropology, 45: 369-436.

DahlberG, A. A. (1963): «Dental evolution and Culture». Human Biology, 35: 237-249.

DEAN, M. C. (1987): "The dental development status of six East African juvenile fossil hominids". Journal of Human Evolution, 16: 197-213.

BEER, DE G. R. (1930): Embriology and Evolution. Clarendon Press. Oxford.

- (1948): "Embriology and the evolution of Man». In A. du Toit (ed.): Robert Broom Commemorative Volume. Special Publications of the Royal Society of South Africa: 181-190.

DemiRjian, A. (1978): «Dentition». In L. Falkner \& J. M. Tanner (eds.): Human Growth, 2, Plenum Press. New York: 413-444.

Dommergues, J. L.; David, B. \& Marchand, D. (1986): «Les relations ontogenése-phylogenése: applications paléontologiques". Geobios, 19: 335-356.

FINK, W. L. (1982): "The conceptual relationship between ontogeny and phylogeny». Paleobiology, 8: $254-264$.

Gould, S. J. (1977): Ontogeny and Phylogeny. Harvard University Press. Cambridge.

GRINE, F. E. (1987): "On the eruption pattern of the permanent incisors and first permanent molars in Paranthropusm. American Journal of Physical Anthropology, 72: 353-359.

- (1989): «New hominid fossils from Swartkrans Formation (1979-1986 excavations): craniodental specimens». American Journal of Physical Anthropology, 79: 409-449.

Harcourt, A. H.; Harvey, P. H.; Larsen, S. L. \& Shat, R. V. (1981): "Testing weight and breeding systems in primates". Nature, 293: 55-57.

Harris, J. M. (1983): "The fossil ungulates: Proboscidea, Perissodactyla and Suidae». Koobi Fora Research Project 2. Clarendon Press. Oxford.

Hemmer, H. (1967): «Der phylogenetische gestaltwandel des hominidenschädels in allometrischer betrachtung». Homo-9. Tagung der Deutschen Gesellschaft für Anthropologie: 139-143.

- (1969): "A new view of the evolution of Man». Current Anthropology, 10: 179-180.

HowELls, W. W. (1976): «Explaining modern Man: evolucionists versus migrationists». Journal of Human Evolution, 5: 447-495.

IsAAC, G. (1983 a): "Aspects of human evolution». In J. M. Harris (ed.): Essays on Evolution: a Darwin Centenary Volume. Cambridge University Press. Cambridge: 32-58.

- (1983b): «Bones in contention: competing explanations for the juxtaposition of Early Pleistocene artifacts and faunal remains". In J. Clutton-Brock \& C. Grigson (eds.): Animal and Archaeology: and Archaeology: Hunters and their Prey. B.A.R. International Series. Oxford: 3-19.

- (1984): "The archaeology of human origins: studies of the Lower Pleistocene in East Africa». In F. Wendorf \& A. Close (eds.): Advances in Old World Archaeology, 3, Academic Press. New York: 1-87.

Johanson, D. C. \& White, T. D. (1979): "A systematic assessment of early African hominids». Science, 203: 321330.

KeITH, A. (1949): «Foetalization as a factor in human evolution». In A new Theory of Human Evolution. Watts. London: 192-201.

KENNEDY, G. E. (1985): «Bone thickness in Homo erectus». Journal of Human Evolution, 14: 699-708.

Kramer, A. (1991): "Modern human origins in Australasia: Replacement or evolution". American Journal of Physical Anthropology, 86: 455-473.

Krogman, W. H. (1972): Child Growth. University Michigan Press. Ann Arbor.

LEAKEY, R. E. F. \& WOOD, B. A. (1973): «New evidence of the Genus Homo from East Rudolf, Kenya». American Journal of Physical Anthropology, 39: 355-368.

- (1974): «New evidence of the Genus Homo from East Rudolf, Kenya». American Journal of Physical Anthropology, 41: 237-244. 
Leakey, R. E. F. \& Walker, A. C. (1985): «Further hominids from the Plio-Pleistocene of Koobi Fora, Kenyaw. American Journal of Physical Anthropology, 67: 135-163.

- (1988): "New Australopithecus boisei specimens from East and West Lake Turkana, Kenyan. American Journal of Physical Anthropology, 76: 1-24.

LEWIN, R. (1982): «How did humans evolve big brains?w. Science, 216: 840-841.

LORENZ, K. (1971): Studies in human and animal behavior. Harvard University Press. Cambridge, Mass.

LOVEJOY, O. (1980): «Hominid origins: The role of bipedalism». American Journal of Physical Anthropology, 52: 250-262.

- (1981): «The origin of Manm. Science, 211: 341-350.

ManN, A. E. (1975): Paleodemographic Aspects of the South African Australopithecines. University of Pennsylvania. Philadelphia.

- (1988): «The nature of Taung dental Maturation». Nature, 333: 123.

MANN, A. E.; LAMPL, M. \& MONGE, J. (1987): «Maturational patterns in early hominids». Nature, 328: 673-674.

MANN, A. E; MONGE, J. \& LAMPL, M. (1990): «Dental caution». Nature, 348: 202.

MARTí, R. D. (1983): «Human brain evolution in an ecological context». Fifty-Second James Arthur Lecture on the Evolution of the Human Brain, 1982. American Museum of Natural History. New York.

MARTíN, R. \& MAY, R. (1981): «Outward signs of breeding». Nature, 212: 339-342.

MCNAMARA, K. J. (1986): «A guide to the nomenclature of heterochrony». Journal of Paleontology, 60: 4-13.

MontAGU, M. F. A. (1962): "Time, morphology, and neoteny in the evolution of man" In M. F. A. Montagu (ed.): Culture and the Evolution of Man, Oxford University Press. New York: 324-342.

Potrs, R. (1982): «Lower Pleistocene site formation and hominid activities at Olduvai Gorge, Tanzania». Ph. D. dissertation, University of Harvard, Cambridge, Massachusets.

- (1983): «Foraging for faunal resources by early hominids at Olduvai Gorge, Tanzania». In J. Clutton-Brock (ed.): Animals and Archaeology: Hunters and their Prey. B.A.R. International Series. Oxford: 51-62.

- (1984): «Home bases and early hominids". American Scientist, 72: 330-347.

- (1988): Early hominid activities at Olduvai. Aldine de Gruyter. New York.

PotTs, R. \& ShIPMAN, P. (1981): "Cutmarks made by stone tools on bones from Olduvai Gorge, Tanzania». Nature, 291: $577-580$.

Schultz, A. H. (1956): «Postembryonic age changes». In H. Hofer, A. H. Schultz \& D. Stark (eds.): «Primatologia» I. Basel S. Karger. New York: 887-964.

SCHINDEWOLF, O. H. (1929): «Das problem der menschwerdung, ein paläontologischer lösungsversuch». Jb. Preuss. Geol. Landesant., 49: 716-766.

SHEA, B. T. (1983): «Allometry and heterochrony in the African apesw. American Journal of Physical Anthropology, 62: 275-289.

- (1989): «Heterochrony in human evolution: The case of neoteny reconsidered». Yearbook of Physical Anthropology, 32: 69-101.

SimPSON, S. W.; Lovejoy, C. D. \& MeINDL, R. S. (1990): «Hominoid dental maturation». Journal of Human Evolution, 19: 285-297.

Sмгтн, B. H. (1986): «Dental development in Australopithecus and early Homon. Nature, 326: 327-330.

SMITH, F. H. (1983): «Behavioral interpretation of changes in craniofacial morphology across the archaic/modern Homo sapiens transition*. In E. Trinkaus (ed.): The Mousterian Legacy: Human Biocultural Changes in the Upper Pleistocene. BAR International Series. Oxford, 164: 141-162.

STRINGER, C. B. \& ANDREWS, P. (1988): "Genetic and fossil evidence for the origin of modern humans». Science, 239: $1.263-1.268$.

Тотн, N. (1982): «The stone technologies of early hominids at Koobi Fora, Kenya: an experimental approach». Ph. D. dissertation, University of California. Berkeley.

VvaA (1985): «L'environnement des Hominidés au Plio-Pleistocènew. Colloque International. Foundation SingerPolignac, 1981. Masson.

WASHBURN, L. (1967): «Behaviour and the origin of man». Huxley Memorial Lecture, 1967. Proceedings of the Royal Anthropological Institute of Great Britain and Ireland: 21-27.

WolPOFF, M. H. (1979): «The Krapina dental remains». American Journal of Physical Anthropology, 50: 67-114.

- (1980): Paleoanthropology. Knopf. New York.

- (1989): «Multiregional evolution: The fossil alternative to Eden». In P. A. Mellars and C. B. Stringer (eds.): The Human Revolution: Behavioural and Biological Perspectives on the Origins of Modern Humans. Edinburgh University Press. Edinburgh: 62-108.

WOLPOFF, M. H.; WU XINZHI \& THORNE, A. G. (1984): «Modern Homo sapiens origins: A general theory of hominid evolution involving the fossil evidence from east Asiaw. In F. H. Smith \& F. Spencer (eds.): The Origins of Modern Humans: A World Survey of the Fossil Evidence. Alan R. Liss. New York: 411-483. 